\title{
Association between glycemic state and pulmonary function and effect of walking as a protective factor in subjects with diabetes mellitus
}

\author{
Ji Min Kim ${ }^{1 \#}$, Min Kyeong Kim ${ }^{1 \#}$, Kyong Hye Joung ${ }^{1}, J_{u}$ Hee Lee ${ }^{1}$, Hyun Jin Kim ${ }^{1}$, Bon Jeong Ku ${ }^{1,2}$ \\ ${ }^{1}$ Department of Internal Medicine, ${ }^{2}$ Department of Medical Science, Chungnam National University College of Medicine, Daejeon, Republic of \\ Korea \\ Contributions: (I) Conception and design: JM Kim, MK Kim, BJ Ku; (II) Administrative support: None; (III) Provision of study materials or patients: \\ JM Kim, MK Kim; (IV) Collection and assembly of data: JM Kim, MK Kim; (V) Data analysis and interpretation: All authors; (VI) Manuscript \\ writing: All authors; (VII) Final approval of manuscript: All authors. \\ \#These authors contributed equally to this work. \\ Correspondence to: Bon Jeong Ku. Department of Internal Medicine, Chungnam National University School of Medicine, 266 Munhwa-ro, Jung-gu, \\ Daejeon 35015, Republic of Korea. Email: bonjeong@cnu.ac.kr
}

\begin{abstract}
Background: Several population-based studies have shown that individuals with type 2 diabetes mellitus (T2DM) have decreased pulmonary function. Moreover, impaired pulmonary function is associated with all-cause mortality in T2DM. We investigated the association between glycemic state and pulmonary function and evaluated the role of walking as protective factor in subjects with diabetes using a nationwide, population-based, cross-sectional survey.

Methods: The study included 17,542 subjects: 2,195 with diabetes, 4,042 with prediabetes, and 11,305 with normal glucose tolerance. Furthermore, 1,770 subjects with available data on walking exercise were divided into three groups according to weekly exercise time: $<150,150-300$, and $\geq 300 \mathrm{~min} /$ week.

Results: The diabetes group had reduced pulmonary function, particularly forced vital capacity (FVC) $(\mathrm{P}<0.001)$, and a decrease in pulmonary function was observed in the subjects with prediabetes $(\mathrm{P}<0.001)$. The walking exercise analysis revealed that the percentage of predicted FVC $(\mathrm{P}=0.001)$ and percentage of predicted forced expiratory volume in $1 \mathrm{~s}(\mathrm{P}=0.021)$ were highest in the subjects with diabetes who walked $\geq 300 \mathrm{~min} /$ week after adjustment for age, sex, body mass index, and waist circumference (WC) measurements. Conclusions: Pulmonary function was significantly associated with walking exercise in diabetic patients, and walking $\geq 300 \mathrm{~min} /$ week may have a preventive effect against pulmonary dysfunction in subjects with diabetes.
\end{abstract}

Keywords: Diabetes mellitus; pulmonary function; walking

Submitted Jul 10, 2019. Accepted for publication Sep 11, 2019.

doi: 10.21037/atm.2019.09.139

View this article at: http://dx.doi.org/10.21037/atm.2019.09.139

\section{Introduction}

Type 2 diabetes mellitus (T2DM) is a complex disease associated with an increased risk of several complications requiring multifactorial intervention to treat and prevent. Cardiovascular disease, nephropathy, retinopathy, and peripheral neuropathy are well-known complications of T2DM. However, recent studies have identified less well- known complications, including cognitive dysfunction (1), mood disorders (2), and sleep-related problems (3). Moreover, several population-based studies found that subjects with T2DM had decreased pulmonary function (4-6), as indicated by lower forced vital capacity (FVC) and forced expiratory volume in $1 \mathrm{~s}\left(\mathrm{FEV}_{1}\right)$ values, regardless of race (4-8). Subjects with impaired fasting glucose levels are 
at higher risk of pulmonary dysfunction (9). Moreover, the findings of several previous studies suggest that decreased pulmonary function may be a predictor of T2DM. Davis et al. (8) found that pulmonary dysfunction was associated with all-cause mortality in T2DM. It is not clear why the decrease in pulmonary function in T2DM increases all-cause mortality, but considering that the decrease in pulmonary function shows an inverse correlation with cardiovascular disease (CVD), the increase in CVD events may also contribute $(10,11)$.

Regular exercise is important for the management of glycemic control in subjects with T2DM (12). Current guidelines recommend that subjects with T2DM perform moderate to vigorous aerobic exercise $(13,14)$; however, such exercise may be difficult for patients with diabetes due to decreased physical abilities (15). Walking is a readily performed and straightforward exercise that does not require special skills or equipment, and the risk of injury or adverse effects is low. Several studies have shown that walking has significant benefits for blood pressure, body weight, and glycemic control (16-18).

Although several previous studies have reported an association between pulmonary function and T2DM, no studies have investigated the prevention of decreased pulmonary function in subjects with diabetes. We investigated the association between glycemic state and pulmonary function and evaluated the role of walking as protective factor in subjects with diabetes

\section{Methods}

\section{Study population}

The Korea National Health and Nutrition Examination Survey (KNHANES) is a nationwide, population-based, cross-sectional survey. KNHANES was designed to assess the health and nutritional status of the Korean population. The survey, which was initiated in 1998, has been conducted periodically by the Korea Centers for Disease Control and Prevention. The KNHANES includes a health questionnaire survey, health examination, and nutrition survey completed by randomly assigned individuals from 600 randomly selected districts in cities and provinces in South Korea. We obtained KNHANES data collected between 2009 and 2013. We initially selected 33,605 subjects aged 19 years or older. Of those, 16,063 subjects with no available pulmonary function or laboratory test data were excluded. Thus, 17,542 subjects were included in the analysis. We divided the subjects into three groups according to disease status: diabetes, prediabetes, and normal glucose tolerance (NGT). Additionally, 1,770 subjects with available data on walking exercise were classified into three groups according to weekly exercise time $(<150,150-300$, and $300 \mathrm{~min} /$ week $)$.

\section{Definition of diabetes and prediabetes}

Diabetes and prediabetes were diagnosed according to the criteria of the American Diabetes Association (19). However, we were not able to assess 2 -h postprandial plasma glucose levels because the oral glucose tolerance test was not included in the KNHANES. We defined diabetes as a fasting plasma glucose (FPG) level $\geq 126 \mathrm{mg} / \mathrm{dL}$, glycosylated hemoglobin (HbA1c) level $\geq 6.5 \%$, or treatment with glucose-lowering medications. Prediabetes was defined as an FPG level of $100-125 \mathrm{mg} / \mathrm{dL}$ or HbA1c level of $5.7-6.4 \%$.

\section{Clinical and biochemical parameters}

Height, weight, and waist circumference (WC) were measured using standard techniques and equipment. Body mass index (BMI) was calculated by dividing weight in kilograms by height in meters squared $\left(\mathrm{kg} / \mathrm{m}^{2}\right)$. Blood pressure was measured manually three times in subjects in the sitting position by nurses experienced in using a mercury sphygmomanometer. The mean of the second and the third measurements was used in the analysis.

Blood samples were collected in the morning after fasting for at least $8 \mathrm{~h}$. FPG was measured using the Hitachi Automatic Analyzer 7600 (Hitachi, Tokyo, Japan). HbA1c was measured using a high-performance liquid chromatography assay (HLC-723G7, Tosoh Co., Tokyo, Japan).

Smoking status, alcohol consumption, physical activity, and histories of disease and medication use were obtained from a self-reported questionnaire. Exercise was categorized according to weekly exercise time (min/week) as highintensity exercise (vigorous aerobic exercise causing vigorous shortness of breath and very fast heart rate for $>10$ min, e.g., running, jumping rope, climbing, and swimming) and moderate-intensity exercise (moderate aerobic exercise causing moderate shortness of breath and slightly fast heart rate for $>10$ min, e.g., brisk walking, jogging, weight training, golf, and Pilates). 


\section{Pulmonary function test}

Pulmonary function was measured by clinical technicians using a dry rolling-seal spirometer (model 2130; Sensor Medics, Yorba Linda, CA, USA). Spirometry tests were repeated up to eight times until at least three acceptable spirometry curves were obtained. $\mathrm{FEV}_{1}$ and FVC measurements were made according to the American Thoracic Society/European Respiratory Society guidelines. We used FVC, $\mathrm{FEV}_{1}$, the $\mathrm{FEV}_{1}$ to $\mathrm{FVC}$ ratio $\left(\mathrm{FEV}_{1} / \mathrm{FVC}\right.$ ), and the percentage of predicted values for $\mathrm{FEV}_{1}\left(\% \mathrm{pFEV} \mathrm{F}_{1}\right)$ and FVC (\%pFVC) to assess pulmonary function.

\section{Statistical analyses}

We performed the normality test using KolmogorovSmirnova test, and we found that some variables including weekly exercise and sitting time, did not meet the normality distribution. Demographic and medical characteristics were compared among groups using the chi-square test, parametric test (one-way analysis of variance followed by a post-hoc Bonferroni correction) and nonparametric test (Kruskal Wallis test and Mann-Whitney U test with Bonferroni correction for post-hoc evaluation). We used analysis of covariance and post-hoc Bonferroni correction to compare pulmonary function among groups, with adjustment for variables that showed significant differences in baseline characteristics in various models. Multivariate linear regression analysis was performed to identify correlations between the glycemic measures (HbA1c and FPG) and pulmonary function-related variables, including $\mathrm{pFVC}, \mathrm{pFEV}_{1}$, and $\mathrm{pFEV}_{1} / \mathrm{FVC}$. Analysis of covariance was used to compare pulmonary function among groups according to walking exercise times. All statistical tests were performed using the Statistical Package for the Social Sciences for Windows, version 18.0 (SPSS Inc., Chicago, IL, USA). Continuous variables are expressed as means \pm standard deviations. $\mathrm{P}$ values $<0.05$ were considered to indicate statistical significance.

\section{Results}

\section{Comparison of baseline characteristics among groups}

The study included 17,542 subjects: 2,195 with diabetes, 4,042 with prediabetes, and 11,305 subjects with NGT. The baseline characteristics of the subjects are shown in Table 1. The highest mean age was in the diabetes group (61.2 years). The diabetes and prediabetes groups comprised more male subjects than did the NGT group. Systolic blood pressure, BMI, and WC were significantly higher in the diabetes group than in the other two groups. The mean FPG and $\mathrm{HbA1c}$ values were $140.6 \mathrm{mg} / \mathrm{dL}$ and $7.3 \%$ in the diabetes group, $107.2 \mathrm{mg} / \mathrm{dL}$ and $5.9 \%$ in the prediabetes group, and $90.0 \mathrm{mg} / \mathrm{dL}$ and $5.6 \%$ in the NGT group, respectively. There was a significant difference among the three groups in hypertension and ischemic heart disease, and alcohol consumption and smoking amount were higher in the diabetes and prediabetes groups than in the NGT group.

\section{Comparison of pulmonary function according to glucose tolerance}

The spirometer results revealed that $\mathrm{FVC}, \mathrm{FEV}_{1}$ and the percentage of predictive values were lowest in the diabetes group and lower in the prediabetes group than in the NGT group (Table 1). After adjustment for potential confounding factors associated with pulmonary function including age, sex, BMI, and $\mathrm{WC}$, the \% $\mathrm{pFVC}$, and $\% \mathrm{pFEV}_{1}$ values were highest in the NGT group and lowest in the diabetes group. In contrast, the $\% \mathrm{pFEV}_{1} / \mathrm{FVC}$ was not significantly different among the groups. The reduced pulmonary function, \%pFVC in particular, in the diabetes group remained significant after further adjustments for current smoking status, high intensity exercise, and walking exercise (Table 2).

\section{Correlation between glycemic parameters and pulmonary function}

We performed a linear regression analysis to investigate the associations between glycemic parameters and pulmonary function. A $1 \%$ absolute increase in the HbA1c level was associated with a $-1.99 \%$ difference in $\%$ pFVC and a $-1.04 \%$ difference in $\% \mathrm{pFEV}_{1}$. A $10 \mathrm{mg} / \mathrm{dL}$ increase in the $\mathrm{FPG}$ level was associated with a $-0.59 \%$ difference in $\% p F V C$ and a $-0.34 \%$ difference in $\% \mathrm{pFEV}_{1}$. After adjusting for confounding factors, the decrement in pulmonary function, $\% \mathrm{pFVC}$ in particular, was significantly correlated with increases in FPG and HbA1c levels. We found that higher HbA1c and FPG levels were independently associated with lower FVC and $\mathrm{FEV}_{1}$ (Table 3).

\section{Effects of walking exercise on pulmonary function in subjects with diabetes}

To further investigate the effects of walking exercise on 
Table 1 Baseline characteristics according to disease status

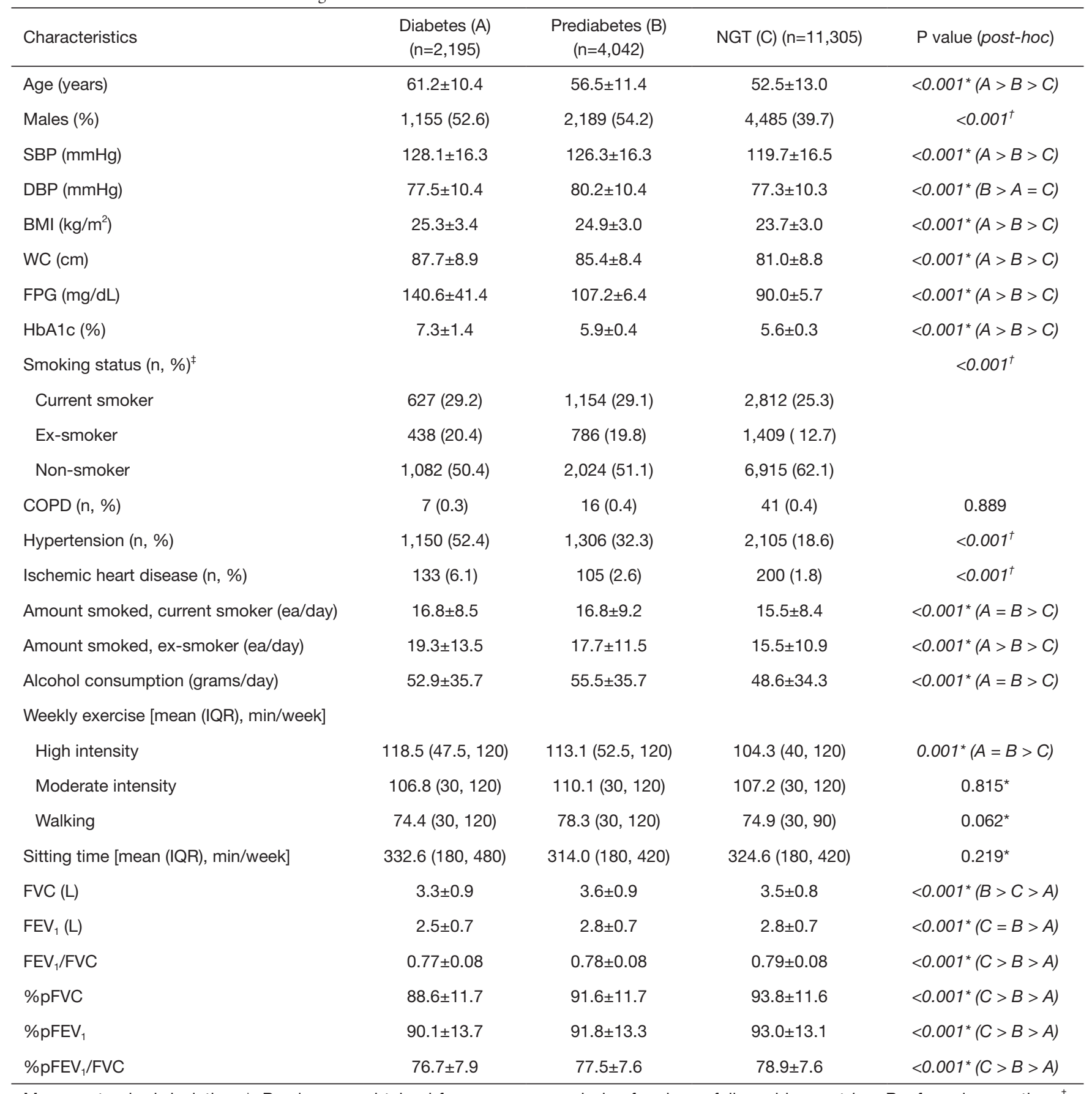

Mean \pm standard deviation. ${ }^{*}, \mathrm{P}$ value was obtained from one-way analysis of variance followed by post-hoc Bonferroni correction; ${ }^{\dagger}$, $P$ value was obtained from the chi-squared test. Ischemic heart disease includes coronary heart disease and angina. Italic numbers indicate statistically significant differences at $\mathrm{P}<0.05$. $^{\ddagger}$, in smoking status, 48, 78, and 169 subjects in Group A, B, and $\mathrm{C}$ did not respond to the questionnaires about smoking status, respectively. Therefore, statistical analyses were performed in $2,147,3,964$, and 11,136 subjects. NGT, normal glucose tolerance; SBP, systolic blood pressure; DBP, diastolic blood pressure; BMI, body mass index; WC, waist circumference; FPG, fasting plasma glucose; HbA1c, glycosylated hemoglobin; COPD, chronic obstructive pulmonary disease; IQR, interquartile range; FVC, forced vital capacity; $F_{E V}$, forced expiratory volume in $1 \mathrm{~s}$; \%pFVC, percentage of predicted FVC; \% $\mathrm{pFEV}_{1}$, percentage of predicted $\mathrm{FEV}_{1}$. 
Table 2 Multivariate analyses of estimated pulmonary function (N=17,542)

\begin{tabular}{|c|c|c|c|c|}
\hline Model & Diabetes $(A)(n=2,195)$ & Prediabetes $(B)(n=4,042)$ & $\operatorname{NGT}(C)(n=11,305)$ & $\mathrm{P}$ value (post-hoc) $)^{*}$ \\
\hline$\% p F V C$ & $90.3 \pm 0.3$ & $92.4 \pm 0.2$ & $93.1 \pm 0.1$ & $<0.001(C>B>A)$ \\
\hline$\%$ pFEV 1 & $90.6 \pm 0.3$ & $92.1 \pm 0.2$ & $92.8 \pm 0.1$ & $<0.001(C>B>A)$ \\
\hline$\% p F E V_{1} / F V C$ & $78.8 \pm 0.1$ & $78.4 \pm 0.1$ & $78.1 \pm 0.1$ & $<0.001(A>B=C)$ \\
\hline \multicolumn{5}{|l|}{ Model 2} \\
\hline$\% p F V C$ & $90.3 \pm 0.3$ & $92.4 \pm 0.2$ & $93.1 \pm 0.1$ & $<0.001(C>B>A)$ \\
\hline$\% \mathrm{pFEV}_{1}$ & $90.6 \pm 0.3$ & $92.1 \pm 0.2$ & $92.8 \pm 0.1$ & $<0.001(C>B>A)$ \\
\hline$\% p F E V_{1} / F V C$ & $78.9 \pm 0.1$ & $78.4 \pm 0.1$ & $78.1 \pm 0.1$ & $<0.001(A>B=C)$ \\
\hline \multicolumn{5}{|l|}{ Model 3} \\
\hline$\% p F E V_{1} / F V C$ & $79.4 \pm 0.3$ & $78.8 \pm 0.2$ & $78.8 \pm 0.1$ & 0.107 \\
\hline \multicolumn{5}{|l|}{ Model 4} \\
\hline$\% p F V C$ & $90.2 \pm 0.3$ & $92.3 \pm 0.2$ & $93.2 \pm 0.1$ & $<0.001(C>B>A)$ \\
\hline$\% p F E V_{1}$ & $90.6 \pm 0.3$ & $91.9 \pm 0.2$ & $92.9 \pm 0.1$ & $<0.001(C>B>A)$ \\
\hline$\% p F E V_{1} / F V C$ & $79.0 \pm 0.2$ & $78.5 \pm 0.1$ & $78.3 \pm 0.1$ & $0.001(A>B=C)$ \\
\hline
\end{tabular}

Mean \pm standard error. ${ }^{*}, \mathrm{P}$ values obtained from analysis of covariance with post-hoc Bonferroni correction. Model 1: adjustment for age, sex, body mass index, and waist circumference; Model 2: same adjustments as in model 1 plus smoking status; Model 3: same adjustments as in model 2 plus high-intensity exercise (time/week); Model 4: same adjustment as in model 2 plus walking exercise (time/ week). Italic numbers indicate statistically significant differences at $\mathrm{P}<0.05$. NGT, normal glucose tolerance; \%pFVC, percentage of predicted forced vital capacity; $\% \mathrm{pFEV}_{1}$, percentage of predicted forced expiratory volume in $1 \mathrm{~s}$.

pulmonary function in subjects with diabetes, we divided the diabetes group into three subgroups according to walking time $(<150,150-300$, and $\geq 300 \mathrm{~min} /$ week) (Table 4). The $\% \mathrm{pFVC}$ and $\% \mathrm{pFEV}$, values were highest in subjects who walked $\geq 300 \mathrm{~min} /$ week. After adjustment for age, sex, BMI, and WC, walking exercise had a significant effect on preventing pulmonary dysfunction in subjects who walked $\geq 300 \mathrm{~min} /$ week. However, we found no significant difference in $\% \mathrm{pFVC1}$ or $\% \mathrm{pFEV}_{1}$ after adjustment for smoking status, suggesting that the beneficial effect of walking on pulmonary function is not independent of smoking. We additionally investigated the effects of walking on pulmonary function in current smokers and nonsmokers, respectively. Similar results were obtained in our analysis of diabetic patients that excluded current smokers. We found that pulmonary function tended to increase in current smokers who walked $\geq 300 \mathrm{~min} /$ week; however, the difference was not statistically significant (data not shown).

\section{Discussion}

We found that pulmonary function was impaired in subjects with diabetes, and that walking exercise had a significant association with pulmonary function. Previous studies have shown that pulmonary function is decreased in subjects with T2DM compared with healthy subjects $(4,20,21)$. The Atherosclerosis Risk in Communities study, a prospective longitudinal study that followed subjects with T2DM for 3 years, found that pulmonary function was significantly reduced in the cohort (22). We confirmed that $\mathrm{FEV}_{1}, \mathrm{FVC}$, and their percentage predictive values were lower in subjects with diabetes than in the control group. Moreover, subjects with prediabetes had lower pulmonary function than that of those with NGT. Taken together, our findings suggest that pulmonary function begins to decrease in the prediabetes state. Diabetes increases the risk of impaired pulmonary function; however, the definitive mechanisms underlying this association remain unclear. Several recent studies 
Table 3 Multivariate adjusted associations of $\mathrm{pFVC}, \mathrm{pFEV}_{1}$, and $\mathrm{pFEV}_{1} / \mathrm{FVC}$ with glycemic measures

\begin{tabular}{|c|c|c|c|c|c|c|c|c|c|}
\hline Traits & \multicolumn{3}{|c|}{$\% p F V C$} & \multicolumn{3}{|c|}{$\% \mathrm{pFEV}_{1}$} & \multicolumn{3}{|c|}{$\% \mathrm{pFEV}_{1} / \mathrm{FVC}$} \\
\hline \multicolumn{10}{|c|}{ HbA1c (1\% absolute increase) } \\
\hline Model 1 & -1.99 & 0.029 & $<0.001$ & -1.04 & 0.006 & $<0.001$ & -0.20 & 0.001 & 0.008 \\
\hline Model 2 & -1.19 & 0.097 & $<0.001$ & -0.84 & 0.04 & $<0.001$ & 0.38 & 0.270 & $<0.001$ \\
\hline Model 4 & -1.30 & 0.095 & $<0.001$ & -0.93 & 0.031 & $<0.001$ & 0.33 & 0.254 & 0.009 \\
\hline Model 5 & -1.20 & 0.098 & $<0.001$ & -0.77 & 0.045 & $<0.001$ & 0.42 & 0.278 & $<0.001$ \\
\hline \multicolumn{10}{|c|}{ FPG (increase of $10 \mathrm{mg} / \mathrm{dL}$ ) } \\
\hline Model 1 & -0.59 & 0.013 & $<0.001$ & -0.34 & 0.003 & $<0.001$ & -0.23 & 0.005 & $<0.001$ \\
\hline Model 4 & -0.30 & 0.068 & $<0.001$ & -0.26 & 0.027 & 0.001 & 0.06 & 0.286 & 0.109 \\
\hline Model 5 & -0.27 & 0.064 & $<0.001$ & -0.21 & 0.033 & $<0.001$ & 0.09 & 0.290 & $<0.001$ \\
\hline
\end{tabular}

Model 1: no adjustments; Model 2: adjustments for age, sex, body mass index, and waist circumference; Model 3: same adjustments as in model 2 plus walking exercise; Model 4: same adjustments as in model 2 plus high-intensity exercise; Model 5: same adjustments as in model 2 plus smoking status. Italic numbers indicate statistically significant differences at $\mathrm{P}<0.05$. \%pFVC, percentage of predicted forced vital capacity; $\% \mathrm{pFEV}_{1}$, percentage of predicted forced expiratory volume in $1 \mathrm{~s}$; FPG, fasting plasma glucose; HbA1c, glycosylated hemoglobin.

have suggested that multiple factors, including low-grade chronic inflammation (23-25), leptin resistance (26,27), and insulin resistance (28), may play roles in the pathogenesis of impaired pulmonary function in T2DM. Given that the lung microvascular structure is composed of an abundance of alveolar-capillary networks, impaired pulmonary function may be a manifestation of diabetic microangiopathy (29). In addition, since T2DM is a significant risk factor for heart failure which can cause the pulmonary function reduction, it could be assumed that cardiovascular diseases, such as hypertension, ischemic heart disease, and heart failure may contribute to impaired pulmonary function in T2DM.

In our diabetes group, the pulmonary function test showed decreases in $\mathrm{FEV}_{1}$ and FVC but a preserved $\mathrm{FEV}_{1} /$ FVC ratio, which is similar to the restrictive pattern previously described in T2DM (30-32). Restrictive lung disease is characterized by a reduced total lung capacity classified as intrinsic or extrinsic according to the cause. Given the pathogenesis described above, intrinsic restrictive ventilatory defects may be primarily attributed to a reduction in pulmonary function in diabetes; however, extrinsic ventilatory defects may also be associated with diabetes because subjects with T2DM have higher rates of obesity and significant muscle weakness.

We found that overall pulmonary function was negatively correlated with FPG and HbA1c levels, and this trend was evident in the NGT and diabetes groups (data not shown). This finding indicates that poor glycemic control increases the risks of pulmonary dysfunction and disease acceleration. Therefore, assessment of pulmonary function is recommended for diabetic patients with poor glycemic control. Furthermore, pulmonary function screening may be clinically useful for diabetic patients with other established risk factors for impaired pulmonary function, such as smoking. Our dataset did not contain information on the duration of diabetes; therefore, we could not determine whether disease duration should be a criterion for pulmonary function screening.

Walking exercise effectively lowers blood glucose levels and blood pressure and improves dyslipidemia $(33,34)$. Moreover, exercise can improve insulin resistance and prevent cardiovascular events via weight loss (18). Furthermore, we demonstrated the possibility of walking exercise as protective factor for pulmonary impairment in subjects with diabetes. We found that walking had a significant effect on preventing pulmonary function decline, 
Table 4 Comparisons of pulmonary function according to walking time in subjects with diabetes

\begin{tabular}{|c|c|c|c|c|c|}
\hline Model & Walking time & $<150 \mathrm{~min} /$ week & 150-300 min/week & $\geq 300 \mathrm{~min} /$ week & $P$ value (post-hoc) \\
\hline \multirow[t]{5}{*}{ Model 1} & FVC & $3.3 \pm 0.8$ & $3.6 \pm 0.8$ & $4.0 \pm 0.9$ & $<0.001(C>B>A)$ \\
\hline & $\mathrm{FEV}_{1}$ & $2.5 \pm 0.7$ & $2.7 \pm 0.7$ & $3.0 \pm 0.6$ & $<0.001(C>B>A)$ \\
\hline & $\mathrm{FEV}_{1} / \mathrm{FVC}$ & $0.77 \pm 0.08$ & $0.75 \pm 0.08$ & $0.75 \pm 0.07$ & $0.011(A>B=C)$ \\
\hline & $\% p F E V_{1}$ & $90.1 \pm 13.7$ & $87.1 \pm 14.0$ & $92.8 \pm 13.5$ & $0.015(C=A>B)$ \\
\hline & $\% \mathrm{pFEV}_{1} / \mathrm{FVC}$ & $76.9 \pm 7.9$ & $75.0 \pm 8.3$ & $75.2 \pm 7.1$ & $0.011(A>B=C)$ \\
\hline \multirow[t]{4}{*}{ Model 2} & FVC & $3.3 \pm 0.8$ & $3.6 \pm 0.8$ & $4.0 \pm 0.9$ & $<0.001(C>B=A)$ \\
\hline & $\mathrm{FEV}_{1}$ & $2.6 \pm 0.7$ & $2.7 \pm 0.7$ & $3.0 \pm 0.6$ & $0.024(C>B=A)$ \\
\hline & $\% \mathrm{pFEV}_{1}$ & $90.1 \pm 13.7$ & $87.1 \pm 14.0$ & $92.8 \pm 13.5$ & $0.021(C>B=A)$ \\
\hline & $\% \mathrm{pFEV}_{1} / \mathrm{FVC}$ & $76.9 \pm 7.9$ & $75.0 \pm 8.3$ & $75.2 \pm 7.1$ & 0.070 \\
\hline \multirow[t]{6}{*}{ Model 3} & FVC & $3.9 \pm 0.8$ & $4.0 \pm 0.7$ & $4.1 \pm 0.8$ & 0.564 \\
\hline & FEV $_{1}$ & $2.9 \pm 0.7$ & $2.9 \pm 0.7$ & $3.1 \pm 0.6$ & 0.583 \\
\hline & $\mathrm{FEV}_{1} / \mathrm{FVC}$ & $0.75 \pm 0.09$ & $0.74 \pm 0.1$ & $0.75 \pm 0.07$ & 0.799 \\
\hline & $\% p F V C$ & $88.8 \pm 11.8$ & $88.2 \pm 10.7$ & $92.8 \pm 12.5$ & 0.477 \\
\hline & $\% p F E V_{1}$ & $86.9 \pm 13.3$ & $84.6 \pm 12.8$ & $89.6 \pm 11.0$ & 0.434 \\
\hline & $\% \mathrm{pFEV}_{1} / \mathrm{FVC}$ & $74.7 \pm 8.7$ & $74.1 \pm 10.0$ & $75.0 \pm 6.8$ & 0.799 \\
\hline
\end{tabular}

*, $\mathrm{P}$ values obtained from analysis of covariance with post-hoc Bonferroni correction. Model 1: no adjustments; Model 2: adjustments for age, sex, body mass index, and waist circumference; Model 3: same adjustments as in model 2 plus smoking status. Italic numbers indicate statistically significant differences at $\mathrm{P}<0.05$. FVC, forced vital capacity; $F_{E V}$, forced expiratory volume in $1 \mathrm{~s}$; \%pFV, percentage of predicted FVC; \%pFEV 1 , percentage of predicted $\mathrm{FEV}_{1}$.

particularly FVC, which was associated with the walking duration per week. Because the $\% \mathrm{pFVC}$ and $\% \mathrm{pFEV}_{1}$ were not significantly different between the $<150$ and 150-300 min/week groups, our findings suggest that subjects with diabetes need to walk $\geq 300 \mathrm{~min} /$ week to prevent a decrease in pulmonary function. Our analysis of walking time and pulmonary function in the NGT group showed that walking did not have a significant effect on pulmonary function (data not shown), suggesting that walking exercise has little impact on individuals whose pulmonary function is not compromised. Although the effect of walking exercise on pulmonary function was not significant in the model adjusted for smoking, together our findings suggest that both walking exercise and smoking cessation are important for improvement of pulmonary function in subjects with diabetes.
Our study has several limitations. First, the retrospective cross-sectional design did not allow for causal conclusions. A prospective longitudinal study is needed to determine the relationship between pulmonary function and duration or severity of diabetes and to confirm the effect of walking exercise on pulmonary function in T2DM. Second, the questionnaire did not distinguish between types 1 and 2 DM; therefore, our diabetes group may have included subjects with type $1 \mathrm{DM}$; however, we were not able to identify differences in pulmonary function or the effectiveness of walking exercise between diabetes types. Moreover, the effect of each type of diabetes on pulmonary function could not be determined. Third, because 2-h postprandial glucose data were not available, subjects with isolated impaired glucose tolerance were included in the NGT group rather than the prediabetes group. However, 
had subjects with isolated impaired glucose tolerance been included in the prediabetes group, we believe that the difference in pulmonary function between the diabetes and NGT groups would have been more marked.

In conclusion, we demonstrated that pulmonary function is decreased in subjects with diabetes, and that impaired pulmonary function is associated with glycemic control. Furthermore, our findings suggest that walking $\geq 300 \mathrm{~min} /$ week can help prevent a decrease in pulmonary function in subjects with diabetes.

\section{Acknowledgments}

Funding: This work was supported by the National Research Foundation of Korea (NRF) grant funded by the Korean Government (NRF-2016R1D1A1A09916900).

\section{Footnote}

Conflicts of Interest: The authors have no conflicts of interest to declare.

Ethical Statement: The authors are accountable for all aspects of the work in ensuring that questions related to the accuracy or integrity of any part of the work are appropriately investigated and resolved. Korea Centers for Diseases Control and Prevention Institutional review board approved this survey and written consent was obtained from all subjects without ethical approval because of the national survey design (IRB No. 2009-01CON-03-2C, 2010-02CON-21-C, 2011-02CON-06-C, 2012-01EXP01-2C, 2013-07CON-03-4C, 2013-12EXP-03-5C).

\section{References}

1. McCrimmon RJ, Ryan CM, Frier BM. Diabetes and cognitive dysfunction. Lancet 2012;379:2291-9.

2. Lustman PJ, Clouse RE. Depression in diabetic patients: the relationship between mood and glycemic control. J Diabetes Complications 2005;19:113-22.

3. Mallon L, Broman JE, Hetta J. High incidence of diabetes in men with sleep complaints or short sleep duration: a 12-year follow-up study of a middle-aged population. Diabetes Care 2005;28:2762-7.

4. Lecube A, Simo R, Pallayova M, et al. Pulmonary Function and Sleep Breathing: Two New Targets for Type 2 Diabetes Care. Endocr Rev 2017;38:550-73.

5. Klein OL, Aviles-Santa L, Cai J, et al. Hispanics/
Latinos With Type 2 Diabetes Have Functional and Symptomatic Pulmonary Impairment Mirroring Kidney Microangiopathy: Findings From the Hispanic Community Health Study/Study of Latinos (HCHS/SOL). Diabetes Care 2016;39:2051-7.

6. Lee YJ, Kim NK, Yang JY, et al. Low pulmonary function in individuals with impaired fasting glucose: the 2007-2009 Korea national health and nutrition examination survey. PLoS One 2013;8:e76244.

7. Klein OL, Kalhan R, Williams MV, et al. Lung spirometry parameters and diffusion capacity are decreased in patients with Type 2 diabetes. Diabet Med 2012;29:212-9.

8. Davis WA, Knuiman M, Kendall P, et al. Glycemic exposure is associated with reduced pulmonary function in type 2 diabetes: the Fremantle Diabetes Study. Diabetes Care 2004;27:752-7.

9. Kim HK, Kim CH, Jung YJ, et al. Association of restrictive ventilatory dysfunction with insulin resistance and type 2 diabetes in koreans. Exp Clin Endocrinol Diabetes 2011;119:47-52.

10. Wang B, Zhou Y, Xiao L, et al. Association of lung function with cardiovascular risk: a cohort study. Respir Res 2018;19:214.

11. Min KB, Min JY. Reduced lung function, C-reactive protein, and increased risk of cardiovascular mortality. Circ J 2014;78:2309-16.

12. Makura CB, Nirantharakumar K, Girling AJ, et al. Effects of physical activity on the development and progression of microvascular complications in type 1 diabetes: retrospective analysis of the DCCT study. BMC Endocr Disord 2013;13:37.

13. Sigal RJ, Kenny GP, Boule NG, et al. Effects of aerobic training, resistance training, or both on glycemic control in type 2 diabetes: a randomized trial. Ann Intern Med 2007;147:357-69.

14. Colberg SR, Sigal RJ, Fernhall B, et al. Exercise and type 2 diabetes: the American College of Sports Medicine and the American Diabetes Association: joint position statement. Diabetes Care 2010;33:e147-67.

15. Weinstock RS, Brooks G, Palmas W, et al. Lessened decline in physical activity and impairment of older adults with diabetes with telemedicine and pedometer use: results from the IDEATel study. Age Ageing 2011;40:98-105.

16. Murphy MH, Nevill AM, Murtagh EM, et al. The effect of walking on fitness, fatness and resting blood pressure: a meta-analysis of randomised, controlled trials. Prev Med 2007;44:377-85.

17. Kelley GA, Kelley KS, Tran ZV. Walking and resting 
blood pressure in adults: a meta-analysis. Prev Med 2001;33:120-7.

18. Qiu S, Cai X, Schumann U, et al. Impact of walking on glycemic control and other cardiovascular risk factors in type 2 diabetes: a meta-analysis. PLoS One 2014;9:e109767.

19. American Diabetes Association. 2. Classification and Diagnosis of Diabetes: Standards of Medical Care in Diabetes-2018. Diabetes Care 2018;41:S13-S27.

20. Walter RE, Beiser A, Givelber RJ, et al. Association between glycemic state and lung function: the Framingham Heart Study. Am J Respir Crit Care Med 2003;167:911-6.

21. Lange P, Parner J, Schnohr P, et al. Copenhagen City Heart Study: longitudinal analysis of ventilatory capacity in diabetic and nondiabetic adults. Eur Respir J 2002;20:1406-12.

22. Yeh HC, Punjabi NM, Wang NY, et al. Cross-sectional and prospective study of lung function in adults with type 2 diabetes: the Atherosclerosis Risk in Communities (ARIC) study. Diabetes Care 2008;31:741-6.

23. Aronson D, Roterman I, Yigla M, et al. Inverse association between pulmonary function and C-reactive protein in apparently healthy subjects. Am J Respir Crit Care Med 2006;174:626-32.

24. Dennis RJ, Maldonado D, Rojas MX, et al. Inadequate glucose control in type 2 diabetes is associated with impaired lung function and systemic inflammation: a crosssectional study. BMC Pulm Med 2010;10:38.

25. Lecube A, Sampol G, Munoz X, et al. TNF-alpha system and lung function impairment in obesity. Cytokine 2011;54:121-4.

Cite this article as: Kim JM, Kim MK, Joung KH, Lee $\mathrm{JH}, \mathrm{Kim} \mathrm{HJ}, \mathrm{Ku}$ BJ. Association between glycemic state and pulmonary function and effect of walking as a protective factor in subjects with diabetes mellitus. Ann Transl Med 2019;7(20):530. doi: 10.21037/atm.2019.09.139
26. Rehman Khan A, Awan FR. Leptin Resistance: A Possible Interface Between Obesity and Pulmonary-Related Disorders. Int J Endocrinol Metab 2016;14:e32586.

27. Hickson DA, Burchfiel CM, Petrini MF, et al. Leptin is inversely associated with lung function in African Americans, independent of adiposity: the Jackson Heart Study. Obesity (Silver Spring) 2011;19:1054-61.

28. Lecube A, Sampol G, Munoz X, et al. Insulin resistance is related to impaired lung function in morbidly obese women: a case-control study. Diabetes Metab Res Rev 2010;26:639-45.

29. Hsia CC, Raskin P. The diabetic lung: relevance of alveolar microangiopathy for the use of inhaled insulin. Am J Med 2005;118:205-11.

30. Ford ES, Mannino DM. Prospective association between lung function and the incidence of diabetes: findings from the National Health and Nutrition Examination Survey Epidemiologic Follow-up Study. Diabetes Care 2004;27:2966-70

31. Klein OL, Krishnan JA, Glick S, et al. Systematic review of the association between lung function and Type 2 diabetes mellitus. Diabet Med 2010;27:977-87.

32. van den Borst B, Gosker HR, Zeegers MP, et al. Pulmonary function in diabetes: a metaanalysis. Chest 2010;138:393-406.

33. Williams PT, Thompson PD. Walking versus running for hypertension, cholesterol, and diabetes mellitus risk reduction. Arterioscler Thromb Vasc Biol 2013;33:1085-91.

34. Fritz T, Wandell P, Aberg H, et al. Walking for exercise-does three times per week influence risk factors in type 2 diabetes? Diabetes Res Clin Pract 2006;71:21-7. 